This item was submitted to Loughborough's Research Repository by the author.

Items in Figshare are protected by copyright, with all rights reserved, unless otherwise indicated.

\title{
How the internet of things technology enhances emergency response
} operations

PLEASE CITE THE PUBLISHED VERSION

http://dx.doi.org/10.1016/j.techfore.2012.07.011

PUBLISHER

(C) Elsevier Inc.

VERSION

AM (Accepted Manuscript)

LICENCE

CC BY-NC-ND 4.0

\section{REPOSITORY RECORD}

Yang, Lili, Shuang-Hua Yang, and L. Plotnick. 2019. "How the Internet of Things Technology Enhances Emergency Response Operations”. figshare. https://hdl.handle.net/2134/14812. 


\title{
How the Internet of Things Technology Enhances Emergency Response Operations
}

\author{
L Yang $^{1^{*}}$, S H Yang ${ }^{2}$ and L Plotnick ${ }^{3}$ \\ ${ }^{1}$ School of Business and Economics, Loughborough University, Loughborough, LE11 3TU, UK \\ ${ }^{2}$ Computer Science Department, Loughborough University, Loughborough, LE11 3TU, UK \\ ${ }^{3}$ Mathematical, Computing \& Information Sciences, Jacksonville State University, Al
} 36265-1602, USA

Abstract-The Internet of Things (IoT) is a novel paradigm that connects the pervasive presence around us of a variety of things or objects to the Internet by using wireless/wired technologies to reach desired goals. Since the concept of the IoT was introduced in 2005 , we see the deployment of a new generation of networked smart objects with communication, sensory and action capabilities for numerous applications, mainly in global supply chain management, environment monitoring and other non-stress environments. This paper introduces the IoT technology for use in the emergency management community. Considering the information required for supporting three sequential and distinct rhythms in emergency response operations: mobilization rhythm, preliminary situation assessment rhythm, and intervention rhythm, the paper proposes a modified task-technology fit approach that is used to investigate how the loT technology

\footnotetext{
*School of Business and Economics, Loughborough University, Ashby Road, Loughborough, Leicestershire LE11 3TU, United Kingdom. Tel: +44 1509 223130; fax: +44 1509 223960. Email address: L.Yang@lboro.ac.uk
} 
can be incorporated into the three rhythms and enhance emergency response operations. The findings from our research support our two hypotheses: H1: IoT technology fits the identified information requirements; and H2: loT technology provides added value to emergency response operations in terms of obtaining efficient cooperation, accurate situational awareness, and complete visibility of resources.

Keywords: Internet of Things, wireless sensor networks, radio frequency identification, emergency response operations, task-technology fit, strategic value. 


\section{How the Internet of Things Technology Enhances Emergency Response Operations}

\section{Introduction}

\subsection{Motivation}

Disasters such as fires, floods, earthquakes, civil war, or terrorist attacks may cause crisis situations. Regardless of the origin, crisis situations are often accompanied by uncertainty of how the disaster will develop, a rapid pace of response operations, and the possibility of serious loss of human lives and property if not responded to properly. Good situational awareness and decision-making support are important factors for minimizing property damage and injury, and for saving people's lives. To provide adequate situational awareness and decision-making support to manage crisis situations, researchers and practitioners in disaster management have urged attention to the development of emergency response information systems (ERISs). Emergency response information systems should support first responders by enhancing their situational awareness which will lead to better decision-making [1]. It is argued that human decision-making failures during catastrophic incidents such as Bhopal [2], the firefighters' deaths during 9/11 [3] and the Three Mile Island nuclear crisis [4] were caused by situational awareness failures and the lack of support of decision-making. Several ERIS development efforts have addressed the importance of enhancing first responder situational awareness and improving their decision support capability [5-8]. Key studies [9-11] that recommended information system (IS) models and architectures suitable for emergency response (ER), have identified the ability of IS to provide support to decision-making and to understanding and recognizing the situation or 
context that responders face as key criteria for design of effective ERISs.

Different than IS for office use, an ERIS may work in an extreme and stress-filled environment, needing not only static information such as road maps and building floor plans, but also dynamic and real time information such as information about the latest disaster developments and the current locations of emergency personnel and resources. As an emergency evolves, requirements (both informational and logistical) may change resulting in necessary modifications of the response workflow $[12,13]$. An investigation of first responders' requirements in a Dutch emergency response case illustrated that much of the information first responders request during a crisis can be considered as dynamic information and needed almost instantaneously [14]. Furthermore, a desirable ERIS platform consists of a number of Mobile Data Terminals (MDT) [15], and many handheld devices such as mobile phones, iPads, personal digital devices (PDA), in cooperation with one or more large-scale computer server systems located in a fixed place. These features make it desirable for ERISs to be global and distributed information systems with the capability of real-time information acquisition, processing, sharing and understanding. To the knowledge of the authors, there are few such large-scale ERISs in use. Actually, many challenging issues involving technical, organizational and human factors and perspectives still need to be addressed before the desirable ERISs will be widely accepted. This paper addresses the information infrastructure issue of the desirable ERISs by introducing Internet of Things (IOT) technology into the emergency management domain, and investigates requirements-technology fit and the value added of using the loT technology in ER 
operations.

\subsection{Concept of the loT}

The concept of the Internet of Things (IOT) is to make every single 'network enabled' object in the world network connected, and represents a vision in which the Internet extends into the real world embracing everyday objects [16]. The term 'Internet of Things' was popularized by the work of the Auto-ID Center at the Massachusetts Institute of Technology (MIT), which in 1999 started to design and propagate across-company radio frequency identification (RFID) infrastructure [17]. One of the definitions of the loT described it as 'a self-configured dynamic global network infrastructure with standards and interoperable communication protocols where physical and virtual 'things' have identities, physical attributes, and virtual personalities, and are seamlessly integrated into the information infrastructure' [18]. The concept of 'things' in the network infrastructure refers to any real or virtual participating actors such as real world objects, human beings, virtual data and intelligent software agents. The purpose of the loT is to create an environment in which the basic information from any one of the networked autonomous actors can be efficiently shared with others in real-time. With more powerful and efficient data collection and sharing ability, such a vision is possible and capable of supporting sophisticated decision support systems by providing services in a more accurate, detailed and intelligent manner. While workflows (descriptions of tasks to be performed, constraints on the tasks including resources needed, and relationships between the tasks) can be static in many applications (e.g. manufacturing), the constantly changing environment and requirements during an 
emergency requires an ability to dynamically alter the workflow in a rapid and correct way [13]. The IoT, with its potential for instantaneous updates of status, requirements, and other information, can enable dynamic workflow adaptations. For example, in [13] a formal approach for dynamic workflow management and analysis (WIFA) is proposed, and extended in [12] to incorporate awareness of changing resource (including people) needs and availability in dynamically creating and modifying workflows. The research of $[12,13]$ developed an intuitive user interface to manage the dynamically changing workflow needs of an emergency. Incorporating the concept of IoT and the technologies that support it, in a system that uses the WIFA approach proposed by $[12,13]$ will enable almost instantaneous changes in information and resources needed to update workflows and therefore enable decision-making about next steps (tasks) to be performed in a way that will make emergency response most effective during all phases of the event.

There are many definitions of the Internet of Things in the research and relevant industrial communities. The definitions may rise from the word 'Internet' and lead to an 'Internet oriented' vision, or 'things' and lead to a 'things oriented' vision. Putting the world 'Internet' and 'Things' together semantically means a world-wide network of interconnected objects uniquely addressable, based on standard communication protocols. Atzori et al. [19] presented this third vision of IoT as 'semantic oriented' and the loT paradigm as a result of the convergence of these three visions. The research roadmap from the European Commission [18] deemed the loT as an integrated part of the future Internet. Some researchers tended to consider the IoT as a separate part of the Internet. Gershenfeld et al. 
[20] described the IoT as an extension of the Internet to reach out to the physical world of things and places that only can support low-end computers, whilst Fleisch [21] argued that the IOT is not on the same level as the Internet, but it is in fact an application of the Internet as are many existing Internet-enabled services. Since the concept of loT was introduced in 2005, we see the deployment of smart 'network enabled' objects with communication, sensory and action capabilities for numerous applications such as in the areas of healthcare [22-24], smart buildings [25], social networks [26], environment monitoring [27], transportation and logistics [28], etc. All applications of the loT rely on the data collected from distributed smart 'network enabled' objects and the loT information infrastructure for data transmission.

The existing studies, however, have not explicitly dealt with the loT as an entire technology for ER operations. Does the use of the IOT technology enhance ER operations? In which way does this enhancement occur? What is the strategic value of the IOT in ER operations? The main purpose of this paper is to provide insight into these questions by investigating the workflow ER operations follow, what information is required in the workflow, how the loT fulfills the information requirements, and how the use of the loT creates sustainable benefits. The focus of the paper is particularly on how the loT technology enhances ER operations by interconnecting the smart 'network enabled' objects, such as fire fighters, fire engines, crisis site, and other emergency resources, included in the loT information infrastructure. 


\subsection{Organization of the paper}

The remainder of the paper is organized as follows. In Section 2, we introduce the loT enabling technologies and the principal emergency related applications. The research method is the subject of Section 3. Section 4 gives a UK based workflow of large-scale ER operations, while the information requirements for supporting these ER operations are derived in Section 5. A modified task-technology fit approach is proposed in Section 6 and employed in the analysis of using the loT technology in ER operations to fulfill the identified information requirements. Section 7 provides insight into the research findings followed by limitations in Section 8. Conclusions and future research plans are given in Section 9.

\section{Technical background}

The IoT is a multi-disciplinary concept that involves research in the fields of hardware, near-field communication, networking, data fusion and decision making. Implementation of the IoT concept into the real world is through the integration of several enabling technologies belonging to these fields. We categorize these enabling technologies in terms of the levels of their competencies [29]:

- Technology level - technologies for connecting real or virtual smart objects within the information infrastructure under strong energy and environmental constraints, i.e. individual wireless sensing capabilities;

- Communication and networking level - technologies for providing the massive secure, dynamic and flexible communication networking;

- Intelligence level - technologies for providing data fusion and service discovery where 
data collected by individual smart 'network enabled' objects such as RFID and wireless sensors are used by distributed users.

\subsection{RFID and wireless sensor network technologies}

The most significant feature of the loT is the capability of embracing everyday 'things' in the physical world in the Internet and enabling interaction between them. This feature is implemented through the key functionalities in the technology level being considered as identification and sensing. The interface between the physical and the digital worlds requires the capacity for the digital world to sense the physical world and to act on it. Continuous progresses in technologies in pervasive and ubiquitous computing such as RFID, sensors, wireless sensor networks (WSNs) are enabling some specific functionality to support the loT. However, simply equipping objects with microchips and retrieving information at a local level is far from enough. These smart 'network enabled' objects extend beyond current 'simple' sensors and RFID or the combination of these two. They are in particular, based on cheap and small wireless devices with sensing, acting, communication, and advanced signal and information processing capabilities.

\subsubsection{RFID}

RFID is an automatic identification technology, which identifies items and gathers data about items without human intervention. RFID is also a wireless technology, which allows item identification and data transmission without physical contact. The most basic components of an RFID system are readers and tags [30]. 
Logistics is one of the main application areas to which RFID systems are considered to be particularly suitable. Researchers have shown that by using RFID, the status of material and vehicles can be autonomously tracked and monitored throughout the supply chain and in logistics centers so as to increase the visibility and delivery reliability in terms of correct material orders and timely deliveries [31]. More and more logistics centers [32-35] are adopting RFID systems to improve performance as RFID systems can accomplish real-time monitoring of almost every link in the logistics management and obtain related information in a timely and accurate way. For example, Wal-mart, the world's largest retailer, has implemented RFID into its supply chain, which gives them the ability to know where every item is in the supply chain [33]. Staake et al. [35] has shown the potential of using RFID systems to protect products against theft and plagiarism. In hospital ER operations, RFID systems have been used in asset tracking and people localization [23, 36, 37]. RFID systems have also been used in humanitarian logistics center management [38], emergency response management [39], and building assessment for urban emergency response and recovery [40].

\subsubsection{WSNs}

Advanced research and development of wireless technology and digital electronic devices has led to the creation of low-cost, low power, multifunctional, small, devices called wireless sensors or sensing nodes with limited communication distances [41]. Large numbers of sensing nodes, which have the ability to communicate wirelessly, form what are called WSNs 
$[42,43]$. There are many types of wireless sensors depending on the type of sensing. A few safety related sensors for sensing are named here: temperature, smoke, gas concentration, pressure, mechanical stress levels on attached objects, and presence or absence of hazard materials, etc. One of the key advantages of WSNs is the capability of their sensor nodes. All sensor nodes are powered by batteries, and can be instantly deployed without needing any previously existing infrastructure.

The services offered by a WSN can be obtained through cooperation between these wireless sensor nodes, and classified into monitoring, tracking, alerting, and information 'on-demand' [44, 45]. Sensor nodes can continuously monitor environmental parameters of their surroundings such as temperature in a room. Sensors can track the position of goods, important equipment and people in real-time, identifying a person or object in motion. Sensors can constantly monitor certain physical conditions and automatically alert the users of the system if an abnormal condition occurs. WSNs can serve as data sources and be queried about the actual level of a certain environmental parameter, providing information "on-demand". These services make these wireless sensors and WSNs very useful for monitoring natural phenomena, detecting environmental changes, controlling security, estimating traffic flows, monitoring military applications, and tracking friendly forces in the battlefields [42].

WSNs have demonstrated their capability of improving the efficiency of ER, by application in emergency medical care [46], in-home healthcare [47], civil infrastructural health monitoring 
[48], and emergency evacuation [49]. WSNs have great potential to provide 'inside building' information. Sensors that are battery-powered, light and cheap can be deployed in the building to monitor the environment, and they can transfer real-time information about the occurrence and spread of an incident (such as a fire) to outside the building [50]. Information on, for example, temperature, smoke ingress, and gaseous composition, can greatly increase the situational awareness of the first responders [51, 52].

In summary, RIFD and WSN technologies make it possible to identify the 'things', sense the environment in the physical world, and build low cost and reliable solutions and services that enable the interconnection of various 'things' in the loT.

\subsection{Wireless communication technologies and Service Oriented Architecture}

There are several standards for developing a WSN and a RFID network and for filling the gap between the physical world and the Internet for the loT. The two commonly used ones are ZigBee [53] and 6LowPAN [43]. Both of them are implemented on top of the IEEE 802.15.4 standard [54]. IEEE 802.15.4 technology is a low data rate, low power consumption, and low cost wireless networking protocol targeted towards automation and remote control applications. The standard defines characteristics of the physical and MAC (medium access control) layers for Low-Rate Wireless Personal Area Networks (LR-WPAN). The main advantages of LR-WPAN are ease of installation; reliable data transfer; short-range operation; extremely low cost; and a reasonable battery life, while maintaining a simple and flexible protocol stack [55]. The ZigBee standard is mainly used in lower powered communication 
devices and in home and industrial applications. The IPv6 over low power wireless personal networks (6LowPAN) standard supports IPv6 and allows direct access to the low powered devices by assigning their own IP address. These two standards can work independently or be interconnected through interconnection technologies such as IPv6 stack for ZigBee [56] or ZigBee-IP [53].

Work has been also carried out to investigate the integration and interconnection of RFID and WSN technologies at the communication and networking level of the loT. Liu [57] used a field bus to connect sensors and RFID readers to a central server, whilst Jedermann et al. [58] designed and implemented a freight agent module to integrate RFID and WSNs in a container for fruit logistics. A further improved system was presented by Yang et al. [38] to seamlessly integrate RFID, sensors and WSNs into a unified ZigBee RFID Sensor Network for humanitarian logistics centre management. However, most of the existing research focuses on a local system design and a single-site and single-purpose implementation. For supporting the global vision of the IoT, well-developed long distance wireless communication technologies such as $3 G$ and WiMAX are needed to link the local sensing systems with the global Internet infrastructure to achieve the scalability and flexibility of serving multiple applications within the scope of a global distributed system. The mobile data terminal (MDT) is an emergency application solution specifically for UK police, ambulance services and emergency response services. The MDT solution is a ruggedized mobile laptop built and installed in fire engines, police cars and ambulances to suit the needs of an extreme environment. It has a reliable wireless connection via $3 G$ using the Internet or intranet for 
remote information access.

Simply adopting the loT enabling technologies such as RFID and WSN in a local system cannot, itself, fulfill the visions of the loT. A global information infrastructure is required for the loT. The architectures proposed for the loT often follow the Service Oriented Architecture (SoA) approach, where complex and monolithic systems are decomposed into publishing, registering, and consuming application functionality, namely services [59]. Service producers and service consumers are not initially designed to fit together but are matched at run time by the SoA middleware. Advantages of the SoA approach include allowing for software and hardware reuse, because it does not impose a specific technology for the service implementation [60], and enhancing the flexibility and simplicity of the system because of the simple and well-defined components.

\subsection{Data fusion and information query technologies}

Data fusion is an information processing technique that aims at associating, combining, aggregating, integrating, and blending data from multiple sources, in order to improve the quality of data or provide better information than individually provided by the original data sources. Information query technologies can be used to obtain the required data. As a global technology the IoT has to provide solutions to distributed data fusion and global data query requests. Unfortunately these areas are less mature compared with the ones at the technology and communication levels. 
Data fusion in the loT can be considered at the decision level or the measurement level. In the first case, the sensor or RFID tag shares with its neighbors a local decision, for example an average value of several measurements, while in the second case they share their raw measurements, i.e. individual measured values. In terms of communication cost, the transfer of raw measurements is general more expensive than a decision. A trade-off between the communication cost and the quality of the decision may be necessary in the case of large-scale and sufficiently dense networks [29].

The nature of the distributed data generated in, or collected from, the loT has also stimulated the concept of a sensor network as a distributed database, which allows any user to issue a query to the sensor network as if it is a database system. Mechanisms to disseminate queries through the network can be realized in a centralized or decentralized way $[61,62]$. In the first case, all data from each node in the network is sent to a large central database. Users can then simply query that database. It could be impractical for a large-scale and dense network because of the communication costs. In the second case, a sensor network only provides information on demand, which can be energy efficient when the query rate is less than the rate at which data is generated. Sensor web enablement (SWE) is a promising standard being developed for information query over the loT with the aim of enabling the discovery of sensors and corresponding observations, exchange and processing of sensor observations, as well as the tasking of sensors and sensor network systems [61]. The term 'sensor' in SWE may include observation archives and simulation data in addition to physical sensors. 


\subsection{Characteristics of the loT technology}

The fundamental characteristics of the loT technology are summarized as follows: (i) the loT is a global and real-time solution; (ii) it is mainly wireless oriented and able to provide comprehensive data about its surroundings in both indoor and outdoor environments; and (iii) it has the ability of remotely monitoring the environment and tracing or tracking objects.

The first fundamental characteristic of the loT technology is that it is a global and real-time solution. First, because the IoT technology is Internet-based or other wide-area network-based, the scope of the IoT has no physical boundary. Any object linked with the network can be incorporated into the loT. Second, the data communication is real-time or almost real-time over the IoT. In that way it is different than traditional databases or web systems.

The second characteristic of the loT is that it is wireless and possesses the ability to provide comprehensive data about the surroundings. RFID sensor networks in the loT integrate RFID networks and wireless sensor networks into a unified information infrastructure. No line of sight is required in RFID sensor networks for their sensing tasks. This feature significantly increases the richness of information.

The third characteristic of the loT is its ability to monitor the environment and trace and track objects. By combining the use of RFID sensor networks with other technologies such as 
Global Positioning System (GPS) or infrared sensor detection, RFID sensor networks provide the ability of wireless, real-time monitoring and tracking of any tagged object in an indoor or outdoor environment to provide complete visibility of the resources. Such visibility enables instant response to any exception event, distributed information sharing among multiple organizations and multiple users, and resource distribution.

\section{Research methods}

The work presented in this paper is part of a completed large-scale multi-disciplinary ER research project in the UK (www.firesafetynet.org.uk). This project as a whole resulted in a novel Goal Directed Information Analysis (GDIA) tool for comprehensive user information requirements capturing [64] and a commercialized ER information system which is comprised of a set of wireless devices and software. This paper presents part of the results of the research project, in particular, the findings on how the loT technology enhances ER operations in general. The key issues addressed in this study are:

- understanding of three key rhythms in ER operations;

- capturing the information required for, but not currently available to, the three rhythms;

- investigating the ways IOT technology enhances ER operations by fulfilling the information required;

- Identifying the strategic value of the loT technology. 
A traditional inductive approach was adopted in this study. Induction is a 'bottom up' approach. The inductive theory approach begins with specific observation and evaluation in order to identify patterns, which are then articulated into tentative hypotheses. Then, based on these hypotheses, general conclusions are developed. Because of lack of control over parameters of the field studies such as the background of fire commanders and fire fighters, and the level of their ICT related experience and knowledge, this study is inductive in nature. The research approach was applied through four stages: preparation, data acquisition, data analysis, and theory induction. The preparation stage is comprised of both the loT technical background review given in the previous section and the data acquisition preparation. Preparation for the data acquisition included securing access to three fire and rescue services (FRSs), and the design of the initial interview scripts and questionnaires. Data gathering methods included interviewing core emergency personnel, shadowing their training sessions, and administering a questionnaire to focus groups. The data analysis stage included translation and re-organization of the records from the data acquisition stage and comparative analysis stage. The theory induction stage was based on a modified task-technology fit approach [65] and mainly focused on mapping the loT technology to the information required in ER operations as identified from both data acquisition and data analysis, and then deriving the value added from the mapping.

The end user group included three emergency response services in the East Midlands region of the UK. They were the Leicestershire fire and rescue service (LFRS), Derbyshire fire and rescue service (DFRS), and Nottinghamshire fire and rescue service (NFRS). Data acquisition 
was conducted over a 12 month period mainly by two researchers, one with an IS and emergency management background and the other one with an loT background. Twenty semi-structured interviews at each FRS with their incident commanders, fire fighters, and staff in a command centre who are not directly involved in frontline duties were conducted. All the interviews were with one individual at a time and took 90 minutes on average with a set of pre-prepared interview questions addressing the above key research issues.

As well as the interviews, three one-hour observations took place in fire fighter training sessions. These observations were used to validate the data collected from the interviews. Three focus groups were held with the majority of the emergency personnel who participated in the interviews. A forum for open discussion was provided and a questionnaire with 72 questions was administered to obtain quantitative information regarding the above research issues. The GDIA tool [64] was employed in the data acquisition and data analysis stages.

\section{Emergency response operations in the UK}

Like most of the countries in the world, the FRSs in the UK have to follow a set of strict work procedures in their ER operations, from handling an emergency call, to dispatching emergency response forces, to on-site preliminary situation assessment, and then to crisis response [66]. These procedures are extensively explained in all kinds of documents, some of which are available for access on the Internet. This section does not aim to provide a further illustration of the ER work practice which is available from many sources $[14,67,68]$, but 
identifies the change of priorities of first responders during the different stages of their operations.

ER operations are triggered by 999 calls handled by a command centre of the FRS in the UK. The command centre has the ability to dispatch police cars, ambulances and fire engines. A certain number of fire engines from the nearest and available fire brigades are dispatched to the incident site. The incident commander, or another staff member assigned to arrive on scene, is responsible for making the decisions for scene management and for calling in additional help if required. Any incident site is physically separated into two parts - an inner and outer cordon. When the first responders arrive at the incident site they mount an inner cordon around the rescue zone into which only specially equipped and trained professionals are allowed [69]. One on-site command post is established to control the ER operations and coordinate the interoperation between all of the organisations present including the FRS, police and medical services. The FRS coordinates its own operations within the inner cordon. The medical services coordinate their activities together with the needs of the FRS and the services of the hospitals. The police coordinate their own activities and secure the boundary from access by the public.

ER operations can be classified into three distinct rhythms. The initial rhythm is the mobilization rhythm in which the fire engines are dispatched by the command centre to the incident site. In this rhythm the priority of the fire crew is to confirm the information received from the command centre and prepare themselves mentally and physically for the 
coming actions. The second rhythm is the preliminary situation assessment rhythm starting with the arrival of the fire crew at the incident site and ending with the completion of the preliminary situation assessment. The priority of the fire crew in this rhythm is to decide the tactical mode and to request additional resources. The third rhythm is the intervention rhythm starting when the physical intervention starts and ending at the completion of ER operations. The priority of the fire crew in this rhythm is reducing the loss caused by the disaster and ensuring the safety of the fire crew. There will be some overlap between the preliminary situation assessment rhythm and the intervention rhythm as some initial physical intervention may happen before the preliminary situation assessment is completed or even immediately on arrival. In most cases, police and ambulance services mainly take part in the intervention rhythm. This classification is similar in spirit to the one proposed by Landgren [67], but with a different definition of the second and third rhythms and the recognition of possible time overlap between these two rhythms.

\section{Information required for supporting ER operations}

There is rich literature identifying information requirements to meet the needs of first responders in their ER operations. Focusing on a Dutch case, Diehl et al. [14] investigated user requirements for the work of the different actors in emergency response including police, fire brigade, ambulance, and municipalities and other institutions. They highlighted the importance of getting real-time and dynamic information about the crisis and exchanging information between different partners at different administrative levels. Starting with specific user requirements collected in Calabria, de Leoni et al. [70] presented more general 
user requirements for supporting communication between control rooms (back-end centers) and on-site rescue teams (front-end teams). Forty two requirements previously identified in emergency and incident management have been ranked in terms of their priorities by Robillard and Sambrook [71]. Using the GDIA [64] information capturing tool, four general categories of information for the UK first responders to support ER operations to a variety of disasters were elicited and a comprehensive list of information requirements of four core members of FRS were given in Yang et al. [52] as part of the research results of the national research project to which this work belongs.

To further describe and classify user requirements, this section provides a tabular model of the information requirements for ER operations, as shown in Table 1. The tabular model presents the information requirements in two dimensions with multiple views. Horizontally, it separates the requirements into two parts: one for front-end teams and another for back-end teams. Front-end teams are directly involved in frontline duties, while back-end teams are located in a command centre which is geographically away from the incident scene. Then the requirements for front-end teams are further classified into mobilization rhythm, preliminary situation assessment rhythm and intervention rhythm in terms of the operation stages in which the information are requested. The components in the vertical dimension include priority of the tasks, category of information, requester of the information, source of information, richness of information, and importance in real-time. For major disasters, the situation might be more complicated than what is described above. For example, some emergency response organizations may join ER operations directly in the intervention 
rhythm. Nevertheless, the requirements for front-end teams will be still classified as the ones shown in Table 1.

Insert Table 1 here

In the above tabular model, environmental conditions refer to any information about the incident scene such as the building structure, the number of occupants or the exact location of any hazard, the trapped victims and the fire fighters inside the building, etc. Information on response participants include who they are and what expertise they are providing. Status of causalities includes the number of causalities, locations, causes and severity, etc. Available resources may include important equipment, food, medicine, and other resources present at the incident scene.

The information characteristics described in the above model can be summarized from the field studies as follows:

- $\quad$ First responders usually have little information about the actual incident status during the mobilization rhythm.

- $\quad$ First responders have little knowledge of what the situation is inside a premise during the preliminary situation assessment rhythm.

- Maintaining the accountability of resources and personnel and tracing their exact locations is not always achievable but essential.

- Decisions could be made much more efficiently and accurately if better situational 
awareness through multiple sources of information is achieved during the intervention rhythm.

- Resource allocation is a primary task for incident commanders and their command centre, but is often carried out less optimally due to the lack of the visibility of resources on the scene or dispatched to other places prior to the incident.

\section{Task-technology fit analysis}

\subsection{Task-technology fit approach}

The task-technology fit approach is applied in this section to link the loT technology with the information requirements identified and to investigate the ways the IOT can enhance ER operations.

A task-technology fit (TTF) approach was suggested by Goodhue and Thompson [65] to understand the linkage between information systems and individual performance. A basic TTF model is illustrated in Fig. 1. In this model, task characteristics refer to the actions carried out by individuals, while technology characteristics refer to the technology used by individuals to perform their tasks. Task-technology fit is a degree to which a technology assists an individual in carrying out his or her tasks. Performance impacts relates to the accomplishment of a portfolio of tasks by an individual. Higher performance implies some mix of improved efficiency, improved effectiveness and/or higher quality.

Insert Fig. 1 here 
Insert Fig. 2 here

In this study we adopt the idea of TTF, but replace 'task' with 'information requirements' and 'technology' with 'loT technology' in the basic model. We also use 'strategic value' to replace 'performance impacts' as the loT technology is new to emergency organizations and has not yet been fully implemented in ER operations. Therefore a simplified model for investigating the ways the loT technology enhance ER operation is proposed in Figure 2. For the sake of the simplicity, we rename 'Information requirements-loT technology fit' as 'requirements-technology fit'. In this model, the following two hypotheses are proposed following the TTF principle:

Hypothesis $1\left(\mathbf{H}_{\mathbf{1}}\right)$ : Adopting the loT technology to deal with the information requirements will have a positive impact in determining the fit between the information requirements and the loT technology.

Hypothesis $2\left(\mathbf{H}_{\mathbf{2}}\right)$ : The fit between the information requirements and the loT technology will have an impact in determining the strategic value of the loT technology in ER operations.

\subsection{Measurement}

Table 2 summarizes the attributes used to measure the characteristics of the information requirements, the IoT technology, requirements-technology fit, and strategic values. Information requirements characteristics and loT technology characteristics were derived from the analysis described in Sections 5 and 2. The aspects of requirements-technology fit considered were derived from the literature on ERIS design. The first three aspects were 
design issues from Jiang et al. [72]: accountability, assessment of situation, and resource allocation. The fourth aspect was one of the design premises from Turoff et al. [12] coordination. Research has shown many benefits of adopting loT related technologies such as RFID [73-76], WSN [44], mobile communication [15] in emergency management and logistics management. Three generic performance impacts, effectiveness, performance and productivity, were suggested by Goodhue \& Thompson [65]. Five benefits (reduced response time, efficient tagging and tracking, compatibility, reduced labor cost, and robustness), were proposed by Ahmed and Sugianto [75], which were expected to be realized by adopting RFID in emergency management. Li and Visich [73] and Tajima [74] compiled a comprehensive list of benefits across the supply chain by using RFID technologies, such as reduced shrinkage, reduced material handling and lower inventory. The aspect of strategic value in the current study is derived from these works but is more abstract and more detailed than described in the earlier literature. The final components of strategic value are (i) efficient cooperation between various organizations, (ii) accurate situational awareness and complete visibility of disaster development, and (iii) complete visibility of response forces and their remaining capability. It is more abstract in the sense that we focus on those benefits achieved by using only the loT technology as an entire solution rather than using individual elements of the IoT related technology in certain independent applications. It is also more detailed in the sense that the strategic benefits achieved are application-specific for ER operations rather than for generic emergency management, logistics supply chain management, policing or environment monitoring. 
Unlike the ordinary task-technology fit approach, this study does not measure the individual attributes listed in Table 1 and therefore, we are unable to statistically test the proposed hypothesizes $\left(\mathrm{H}_{1}\right.$ and $\left.\mathrm{H}_{2}\right)$. This is because of limited research resources. Instead, we directly measure the relationships between information requirements characteristics (IRC), IOT technology characteristics (ITC), requirements-technology fit (RTF), and strategic values (SV) through a questionnaire. For the field studies, the questions in the questionnaire took two types of formats. The questions that tested $\mathrm{H}_{1}$ used Format 1 , and the questions that tested $\mathrm{H}_{2}$ used the Format 2 (both shown below).

Format 1: If ITC $(j=1,2,3)$ is adopted in ER operations to deal with $I R C_{i}(i=1,2,3,4,5)$, how much do you agree $R T F_{k}(k=1,2,3,4)$ will be achieved?

Format 2: If $\operatorname{RTF}_{i}(i=1,2,3,4)$ is true, how much do you agree $S V_{j}(j=1,2,3)$ will be achieved? The questionnaire is comprised of 72 questions, in which 60 questions $(5 \times 4 \times 3)$ used Format 1 and 12 questions $(4 \times 3)$ used Format 2 . Sixty emergency personnel, including incident commanders and fire fighters, participated in the questionnaire. All of the answers to the questions in the questionnaire were measured on a 5-point Likert-type scale with the two extremes of 'strongly disagree $=1$ ' and 'strongly agree $=5$ '. This kind of adaptation is not uncommon in this type of task-technology fit research work.

The answers to the questionnaire are summarized in Tables 3 and 4, named effect matrix, 
where the rows in Table 3 indicate the five information requirements characteristics $I R C_{i}(i=1$, $2,3,4,5)$, and the columns indicate the four requirements-technology fits $R T F_{k}(k=1,2,3,4)$. Each RTF column is further divided into the three loT technology characteristics $\operatorname{ITC}_{j}(j=1,2$, 3). Each cell in Table 3 is the mean of the answers to the corresponding question using Format 1. For example, 'if $I T C_{j}$ is adopted to deal with $I R C_{i}{ }^{\prime}$ ' the mean of the answers to $R T F_{k}$ is recorded at cell $(i,(k-1) \times 3+j)$. Similarly, the rows in Table 4 indicate requirements-technology fit $R \operatorname{TF}_{i}(i=1,2,3,4)$, and the columns indicate strategic values $S V_{j}$ $(j=1,2,3)$. Each cell in Table 4 is the mean of the answers to the corresponding questions using Format 2. For example, if $R T F_{i}$ is true, the mean of the answers of $S V_{j}$ being achieved is recorded at cell $(i, j)$.

Insert Table 3 here

Insert Table 4 here

\subsection{Results analysis}

The effect matrixes in Tables 3 and 4 illustrate the degree to which the loT technology assists ER operations in fulfilling information requirements and generating strategic value, respectively. In order to simplify the results analysis, we apply the following transfer function to each cell of these two effect matrixes,

$$
\text { Binary }(\text { value }- \text { of }- \text { cell })= \begin{cases}1, & \text { value }- \text { of }- \text { cell } \geq 4 \\ 0, & \text { value }- \text { of }- \text { cell }<4\end{cases}
$$


Therefore, Tables 3 and 4 are then transformed into two binary effect matrixes (Tables 5 and 6.) The cells with ' 1 ' show that the degree of agreement is 'agree' or 'strongly agree', and the cells with ' 0 ' show that the degree of agreement is 'neutral' or 'disagree', or 'strongly disagree'. We argue that starting with the 5-point Likert-type scale and then transforming to the binary scale is more accurate than directly measuring the answers to the questionnaire in a binary scale, i.e. agree (1) or disagree (0).

Insert Table 5 here

Insert Table 6 here

The results analysis in terms of the binary effect matrix can be carried out in the following two steps:

Step 1: Check each role in the binary effect matrix. If there is a zero row, i.e. all the cells in a row are zero, then the attribute corresponding to the zero row has no impact on any column attribute; otherwise, all of the row attributes have impact on the column attributes.

Step 2: Check each column in the binary effect matrix. If there is a zero column, i.e. all the cells in a column are zero, then the entire row attributes have no impact on the attribute corresponding to the zero column; otherwise, all of the column attributes can be achieved.

There is a special step for Table 5 due to the three characteristics involved, that is:

Step 3: If there is at least one none zero column in a RTF section, this particular RTF attribute is achievable; otherwise, unachievable. 
By applying the above Steps 1 and 3 to Table 5, we can conclude: (a) all the requirements-technology fits $\left(\mathrm{RTF}_{1}, \mathrm{RTF}_{2}, \mathrm{RTF}_{3}, \mathrm{RTF}_{4}\right)$ are achievable as there is at least one non-zero column in each RTF section; (b) all the information requirements characteristics $\left(I R C_{1}, I R C_{2}, I R C_{3}, I R C_{4}, I R C_{5}\right)$ can be handled with a certain number of loT technology characteristics (ITC) and contribute to one or more requirements-technology fit (RTF) attributes as there does not exist a zero row in Table 5. Therefore, Hypothesis $\mathrm{H}_{1}$ is supported. In detail:

- Accountability of resources and personnel $\left(\mathrm{RTF}_{1}\right)$ is achieved by

$\circ$ the global and real-time IoT characteristic $\left(I \mathrm{IC}_{1}\right)$, dealing with the lack of information on the way to scene $\left(I R C_{1}\right)$, and maintaining the accountability of resources and personnel $\left(\mathrm{IRC}_{3}\right)$, and

$\circ$ the loT ability of monitoring, tracing and tracking objects $\left(\mathrm{ITC}_{3}\right)$, dealing with the lack of information on the way to scene $\left(I R C_{1}\right)$, and inside a premise $\left(I R C_{2}\right)$, and maintaining the accountability of resources and personnel $\left(\mathrm{IRC} \mathrm{C}_{3}\right)$.

- Assessment of the situation $\left(\mathrm{RTF}_{2}\right)$ is achieved by

- the global and real-time loT characteristic $\left(\mathrm{ITC}_{1}\right)$, dealing with situational awareness (IRC 4$)$, and

O the loT ability of both providing comprehensive type of environmental information $\left(I \mathrm{TC}_{2}\right)$ and providing monitoring, tracing and tracking objects $\left(\mathrm{ITC} \mathrm{C}_{3}\right)$, dealing with the lack of information inside a premise $\left(I R C_{2}\right)$, maintaining the 
accountability of resources and personnel $\left(\operatorname{IRC} C_{3}\right)$, and situational awareness $\left(\mathrm{IRC}_{4}\right)$.

- Resource allocation $\left(\mathrm{RTF}_{3}\right)$ is achieved by

○ the global and real-time IoT characteristic $\left(I T C_{1}\right)$, dealing with maintaining the accountability of resources and personnel $\left(\operatorname{IRC} C_{3}\right)$, and the lack of the visibility of resources on scene or dispatched to other places early $\left(\operatorname{IRC} C_{5}\right)$, and

- the loT ability of monitoring, tracing and tracking objects $\left(\mathrm{ITC}_{3}\right)$ dealing with the lack of information on the way to scene $\left(\mathrm{IRC}_{1}\right)$, maintaining the accountability of resources and personnel $\left(\mathrm{IRC} C_{3}\right)$, and the lack of the visibility of resources on scene or dispatched to other places early $\left(\mathrm{IRC}_{5}\right)$.

- Coordination among different participating organizations $\left(\mathrm{RTF}_{4}\right)$ is achieved by

0 the global and real-time IoT characteristic $\left(\mathrm{ITC}_{1}\right)$ and the loT ability of both providing comprehensive type of environmental information $\left(\mathrm{ICC}_{2}\right)$ and providing monitoring, tracing and tracking objects $\left(\mathrm{ICC}_{3}\right)$ dealing with situational awareness $\left(\mathrm{IRC}_{4}\right)$.

Similarly, by applying the above Steps 1 and 2 to Table 6, we can conclude: all the strategic values $\left(\mathrm{SV}_{1}, \mathrm{SV}_{2}\right.$, and $\left.\mathrm{SV}_{3}\right)$ are achievable as there are no zero columns in Table 6 , i.e. Hypothesis $\mathrm{H}_{2}$ is supported. In detail, efficient cooperation between various organizations $\left(\mathrm{SV}_{1}\right)$ and complete visibility of response forces and their remaining capability $\left(\mathrm{SV}_{3}\right)$ are achieved through accurate and real-time accountability of resources and personnel (RTF 1 ), well-supported resource allocation $\left(\mathrm{RTF}_{3}\right)$, and well-supported coordination by the ERIS 
$\left(\mathrm{RTF}_{4}\right)$. Similarly, accurate situational awareness and complete visibility of disaster development $\left(\mathrm{SV}_{2}\right)$ is achieved through well-supported indoor and outdoor situation assessment $\left(\mathrm{RTF}_{2}\right)$.

\section{Research findings}

In this paper we have explored how the loT technology might enhance ER operations by meeting their information requirements and what strategic value can be obtained. Four attributes of requirements-technology fit and three of strategic value were chosen because they are extremely prominent in the literature, and are also very much at the forefront of UK ER operations. However, it must be recognized that the list of the attributes of requirements-technology fit and strategic value is by no means complete. Every new loT implementation, and its applications in different categories of ER operations, will be very different, and therefore may require a different requirements-technology fit attribute or similar attributes in a modified form, and may generate a different strategic value attribute. Attributes of requirements-technology fit actually indicate opportunities for the loT technology to facilitate ER operations, and taking these opportunities may add value to ER operations.

The research findings of this paper support the two hypotheses in our proposed research model for the loT technology in Fig.2, as described below:

Supported Hypothesis 1 - The IoT technology can enhance ER operations from the following four perspectives. 
(i) Accountability of resources and personnel. Accurate and real-time accountability ensures that there is an accurate count of resources and personnel on the scene or on the way to the scene. A lack of accountability can lead to dangerous situations where it is not recognized that resources or personnel are missing [72]. The loT technology provides a global and real-time solution for monitoring, tracing and tracking resources and personnel on the scene, even inside a premise or on the way to the scene. This solution not only works in outdoor environments with high-visibility, but also in indoor environments in poor-visibility conditions [77]. Therefore the loT technology offers accurate and real-time accountability of resources and personnel to ER operations.

(ii) Assessment of the situation. Enhanced situational awareness leads to better decision-making in ER operations [1]. The loT technology possesses the ability to provide real-time and comprehensive data about the incident scene via wireless sensor networks, RFID and other techniques. Therefore, fast and accurate situational awareness can be achieved by gathering these comprehensive data and presenting them to emergency personnel $[50,52]$.

(iii) Resource allocation. Effective ER operations rely on sufficient supplies of emergency responding personnel and resources [38]. The loT technology provides for visibility of response personnel and their remaining resources through its ability of remote monitoring, tracing and tracking. Therefore resources can be most efficiently allocated and delivered to the disaster scene. Furthermore, resource allocation increases the capability of ER operations by making the limited resources available to more ER operations. This finding extends the IoT application from mainly logistics supply chain management to dynamic 
resource allocation.

(iv) Multi-organizational coordination. ER operations require the participation of a wide range of organizations, including fire brigades, police forces, ambulance services, local or national public sectors, and humanitarian aid organizations, etc. Extensive information and resource sharing between separate organizations is crucial to the success of ER operations [78]. The IoT technology provides real-time information on disaster development and the remaining resources of each participating organization, as well as an information sharing infrastructure. Multi-organizational coordination could be well supported by the rich information provided by the loT information infrastructure.

Supported Hypothesis 2 - ER operations enhanced by the above four perspectives can achieve the following three aspects of strategic value: (i) efficient cooperation between various organizations; (ii) accurate situational awareness; and (iii) complete visibility of response forces and their remaining capabilities. Strategic value is realized in three ways: information sharing, information retrieving, and information explanation, and contributed to by the characteristics of the loT technology.

Based upon the above analysis, it can be argued that this paper makes a number of important contributions to both IOT and ER communities in terms of what opportunities are offered to the loT technology, and how and why the loT technology can enhance ER operations. The two supported hypotheses illustrate the usefulness of the IOT in ER operations. 


\section{Limitations}

There are four limitations to this study. First, much of the literature integrates the task-technology (TTF) model with the technology acceptance model (TAM) and discusses determinants of users' intention to adopt a particular technology $[79,80]$. This paper does not discuss technology acceptance issues under the assumption that the loT technology would be adopted by first responders if available. Our future work will examine this assumption in detail by incorporating TAM with TTF. Second, the effect matrixes in Tables 3 and 4 directly record the potential impact between causal attributes and consequent attributes, which makes the analysis of results much simpler than if path analysis and structural equation modelling were used (SEM) [81]. Also, the three individual attributes of IRC, ITC and RTF are combined in a single question, and some of the respondents may find it difficult to answer the questions. This limitation could be overcome by providing the respondents a clear explanation for each question. Third, like other task-technology fit approaches, candidate attributes shown in Table 1 such as possible strategic value and requirements-technology fit, must be proposed before any test takes place. There is a no systematic way to derive possible strategic value and requirements-technology fit. Finally, we did not use statistic analyses such as factor loading, composite reliability and regression coefficient calculation in this study as we did not intend to build a structural equation model and quantitatively test the hypotheses $\left(\mathrm{H}_{1}\right.$ and $\left.\mathrm{H}_{2}\right)$. Because of this simplification, this study is not able to provide a statistical test result for each hypothesis. We classify this modified task-technology fit approach as one between quantitative and qualitative studies. 


\section{Conclusions and future work}

The IoT technology has many positive impacts on every stage of ER operations from the mobilization rhythm, preliminary situation assessment rhythm, all the way to the intervention rhythm. It enhances cooperation between various participating organisations, improves situational awareness, and enables complete visibility of response force and their remaining resources, thus providing for faster and more efficient and effective ER operations.

This paper presents a novel and simple way of analyzing and understanding how the loT technology enhances ER operations and what strategic value can be obtained by assessing the fit between the IoT technology and the information requirements of ER operations through a modified task-technology fit analysis. We argue that this paper makes contributions to knowledge from both theoretical and practical perspectives. From a theoretical perspective, this paper contributes to knowledge by proposing a modified task-technology fit approach which is simple and does not need rigorous statistic analysis. From a practical perspective, this paper contributes to knowledge by introducing the IoT technology to the ER community and by identifying the ways the loT technology enhances ER operations and the strategic value which may be realized.

As discussed previously, technology acceptance issues must be taken in consideration in future work. It was evident from Yang et al. [11] that fire and other emergency personnel have an almost paradoxical relationship with new technologies. Many of them lack the incentive to use new technologies in real operations, and are worried about the reliability 
and procrastinate in adopting them. Alleviating this fear of emergency personnel could directly contribute to the acceptance of the loT technology in ER operations. Another obstacle which slows down, if not stops, the adoption of the loT technology in ER operations is the potential for security risks. Emergency personnel will resist the loT as long as public confidence that it will not cause serious threats to privacy and information security is lacking. Generally speaking, the possible threats of a widespread adoption of such a technology are that 'to the extent that everyday objects become information security risks; the loT could distribute those risks far more widely than the Internet has to date' [19]. The loT is extremely vulnerable to attacks because of characteristics such as being wireless, having unattended components, and possessing low capabilities in terms of both energy and computing resources and thus, complex security measures cannot be implemented.

In closing, we anticipate that research on the loT technology will continue to evolve over the next decade. More characteristics of the loT technology such as new sensing, communication and information processing and data query over the loT may become available. New approaches and models for systems support of managing emergencies and the information required, e.g. WIFA described in $[12,13]$ may become available that can benefit from the use of the loT technology. Investigation into the use of this technology in ER operations should include a variety of approaches, reflecting methodologies using both technical and non-technical perspectives.

\section{Acknowledgement}


The work was financially supported by the Technology Strategy Board (TSB) in the UK through the SafetyNET project (TP/3/PIT/6/I/16993). Appreciation also goes to the Derbyshire, Leicestershire, and Nottinghamshire Fire and Rescue Service Brigades, and the UK Fire Protection Association for their support of this research and allowing the authors to conduct field studies and questionnaire with them.

\section{References}

[1] M. Klann, Tactical Navigation Support for Firefighters: The LifeNet Ad-Hoc Sensor-Network and Wearable System, Proceedings of the Second International Workshop on Mobile Information Technology for Emergency Response (Mobile Response 2008), Bonn, Germany, 2008, 4156.

[2] M.R. Endsley, Situation Awareness and Human Error: Designing to Support Human Performance, Proceedings of the High Consequence Systems Surety Conference, Albuquerque. NM, USA, 1999.

[3] J. Son, Z. Aziz, F. Pena-Mora, Supporting Disaster Response and Recovery Through Improved Situation Awareness, Structural Surev. 26(5) (2007) 411425.

[4] M. Itoh, T. Inagaki, Design of Human-Interface for Situation Awareness II Interdependence between Control Panel and Alarm Systems. In: Proceedings of the 6th IEEE International Workshop on Robot and Human Communication (RO-MAN'97). Sendai, Japan, 1997, 308313.

[5] B. Betts, R. Mah, R. Papasin, R. Del Mundo, D.M. Mclntosh, C. Jorgensen, Improving Situational Awareness for First Responders via Mobile Computing, Syst. Res. 7(October) (2005) 17.

[6] V. Lanfranchi, N. Ireson, User Requirements for a Collective Intelligence Emergency Response System, Proceedings of the 2009 British Computer Society Conference on Human-Computer Interaction, 
Cambridge, UK, 2009, 198203.

[7] G. R. Madey, G. Szabo, A.L. Barabasi, WIPemergency response: The Integrated Wireless Phone Based Emergency Response System, Proceedings of the 6th International Conference on Computational Science (ICCS 2006), Reading, UK, 2006, 417424.

[8] F. Bergstrand, J. Landgren, Using live video for information sharing in emergency response work. Int. J. Emerg. Manage., 6(3/4) (2009) 295-301.

[9] M.E. Jennex, Modeling Emergency Response Systems, Proceedings of the 40th Annual Hawaii International Conference on System Sciences (HICSS 2007), Big Island, Hawaii, 2007, 18.

[10] M. Turoff, M. Chumer, B. Van de Walle, X. Yao, The Design of a Dynamic Emergency Response Management Information System (DERMIS), J. Inf. Technol. Theory and Appl. (JITTA), 5(4) (2004) 1-35.

[11] L. Yang, G. Su, H. Yuan, Design Principles of Integrated Information Platform for Emergency Responses: The Case of 2008 Beijing Olympic Games, Inf. Syst. Res., (2012) in press. Electronic text at, http://isr.journal.informs.org/content/early/2011/11/03/isre.1110.0387.full.pdf+html (last accessed in February 2012)

[12] J. Wang, W, Tepfenhart, D. Rosca, Emergency Response Workflow Resource Requirements Modeling and Analysis., IEEE Trans. on Syst., Man and Cybern., Part C, 39(3) (2009) 114.

[13] J. Wang, D. Rosca, W. Tepfenhart, A. Milewski, M. Stoute, Dynamic Workflow Modeling and Analysis in Incident Command Systems., IEEE Trans. on Syst., Man and Cybern., Part A, 38(5) (2008) 10411055.

[14] S. Diehl, J.M.M. Neuvel, S. Zlatanova, H.J. Scholten, Investigation of user requirements in the emergency response sector: the Dutch case. Second Symposium on Gi4DM, Goa, India (2006), CD ROM, 6 pages.

[15] R. Lindsay, L. Cooke, T. Jackson, The impact of mobile technology on a UK police force and their knowledge sharing, J. Inf. Knowl. Manage., 8(2) (2009) 101112. 
[16] F. Mattern, C. Floerkemeier, From the Internet of Computers to the Internet of Things, Informatik-Spektrum 33 (2) (2010) 107121.

[17] S. Sarma, D.L. Brock, K. Ashton, The networked physical world, TR MIT-AUTOID-WH-001, MIT Auto-ID Center, (2000).

[18] European Commission, Internet of things strategic research roadmap, (2009), Electronic text at, http://www.internet-of-things-research.eu/pdf/loT_Cluster_Strategic_Research_Agenda_2009.pdf (last accessed in February 2012)

[19] L. Atzori, A. lera, G. Morabito, The Internet of Things: A Survey, Comput. Netw., 54(15) (2010) 27872805.

[20] N. Gershenfeld, R. Krikorian, D. Cohen, The Internet of Things, Sci. American. 291 (4) (2004) 7681.

[21] E. Fleisch, What is the Internet of Things? An Economic Perspective, Auto-ID Labs White Paper WP-BIZAPP-053, (2010), Electronic text at, http://www.autoidlabs.org/uploads/media/ AUTOIDLABS-WP-BIZAPP-53.pdf (last accessed in February 2012)

[22] D. Niyato, E. Hossain, S. Camorlinga, Remote patient monitoring service using heterogeneous wireless access networks: architecture and optimization, IEEE J. Sel. Areas in Commun. 27 (4) (2009) 412423.

[23] A. Oztekin, F.M. Pajouh, D. Delen, L.K. Swin, An RIFD network design methodology for asset tracking in healthcare, Deci. Support Syst., 49 (1) (2010) 100109.

[24] C.W. Thompson, F. Hagstrom, Modeling Healthcare Logistics in a Virtual World, IEEE Internet Comput., 12 (5) (2008) 100104 .

[25] M. Darianian, M.P. Michael, Smart home mobile RFID based Internet-Of-Things Systems and services, Advanced Computer Theory and Engineering, ICACTE'08, Phuket, Thailand,( 2008), 116120.

[26] E. Welbourne, L. Battle, G. Cole, K. Gould, K. Rector, S. Raymer, M. Balazinska, G. Borriello, Building the internet of things using RFID: the RFID ecosystem experience, IEEE Internet Comput. 13 (3) (2009) 4855. 
[27] A. Llic, T. Staake, E. Fleisch, Using sensor information to reduce the carbon footprint of perishable goods, IEEE Pervasive Comput., 8 (1) (2009) 2229.

[28] G. Broll, E. Rukzio, M. Paolucci, M. Wagner, A. Schmidt, H. Hussmann, PERCl: pervasive service interaction with the internet of things, IEEE Internet Comput., 13 (6) (2009) 7481.

[29] Association Instituts Carnot, White paper: Smart networked objects \& Internet of Things, 2011 Electronic text at, $\quad$ http://www.instituts-carnot.eu/files/AiCarnot-White Paper-Smart Networked Objects and Internet of Things.pdf (last accessed in February 2012)

[30] A. Jules, RFID security and privacy: a research survey, IEEE J. Sel. Areas in Commun. 24(2) (2006) 381394.

[31] F. Hamzeh, I.D. Tommelein, G. Ballard, P. Kaminsky, Logistics Centers to Support Project-based Production in the Construction Industry, in: C.L. Pasquire and P. Tzortzopoulos (Eds), Proceedings of the 15th Annual Conference of the International Group for Lean Construction (IGLC 15), East Lansing, MI., 2007, 181191.

[32] E.W.T. Ngai, T.C.E. Cheng, S. Au, K. Lai, Mobile commerce integrated with RFID technology in a container depot, Decis. Support Syst., 43 (1) (2007) 6276.

[33] M. Roberti, Case study, Wal-mart's race for RFID, 2003, Electronic text at, http://www.eweek.com/c/a/ Enterprise-Applications/Case-Study-WalMarts-Race-for-RFID/ (last accessed in February 2012)

[34] F. Shu, W. Mi, Z. Xu, The Information Sharing Platform for Port Container Terminal Logistics using Virtual Reality, Proceedings of 2007 IEEE International Conference on Automation and Logistics, Jinan, China, (2007) 25702575.

[35] T. Staake, F. Thiesse, E. Fleisch, Extending the EPC network: the potential of RFID in anti-counterfeiting, In L.M. Liebrock (Eds.), Proceedings of the 2005 ACM Symposium on Applied Computing. Santa Fe, New Maxico, 2005, 16071612. 
[36] I. D'Souza, W. Ma, C. Notobartolo, Real-Time Location Systems for Hospital Emergency Response , IT Prof., 13(2) (2011) 3743.

[37] C.-H. Chien, S.-N. Yu, Y.-Y. Huang, F.-C. Chong, An efficient framework of emergency response to facilitate disaster recovery for fire-damaged medical equipment - Case study at a large medical centre after a fire , Saf. Sci., 49(5) (2011) 727734.

[38] H.J. Yang, L. Yang, S.H. Yang, Hybrid Zigbee RFID sensor network for humanitarian logistics centre management, J. Netw. and Comput. Appl., 34(3) (2011) 938948.

[39] T. Tran, F.Z. Yousaf, C. Wietfeld, RFID Based Secure Mobile Communication Framework for Emergency Response Management, Wireless Communications and Networking Conference, Sydney, Australia, (2010) 16.

[40] Z. Aziz, F. Peña-Mora, A. Chen, T. Lantz, Supporting urban emergency response and recovery using RFID-based building assessment , Disaster Prev. and Manage., 18(1) (2009) 3548.

[41] I.F. Akyildiz, W. Su, Y. Sankarasubramaniam, E. Cyirci, A Survey on Sensor Networks, IEEE Commun. Mag., 40(8) (2002) 102114

[42] K. Romer, O. Kastin, F. Mattern, Middleware Challenges for Wireless Sensor Networks, Mob. Comput. and Communication Review, 6(2) (2002) 12.

[43] IETF, IPv6 over IEEE 802.15.4 low-power wireless personal-area-network, 2007, Electronic Text at, http://www.6lowpan.org (last accessed in February 2012)

[44] R. Roman, C. Alcaraz, J. Lopez, The role of wireless sensor networks in the area of critical information infrastructure protection, Inf. Secur. Tech. Rep., 12(1) (2007) 2431.

[45] R. Shorey, A. Ananda, M.C. Chan, W. T Ooi, Mobile, Wireless, and Sensor Networks, John Wiley \& Sons, Hoboken, NJ, 2006. 
[46] D. Malan, T. Fulford-Jones, M. Welsh, S. Moulton, CodeBlue: An Ad Hoc Sensor Network Infrastructure for Emergency Medical Care, MobiSys 2004 Workshop on Applications of Mobile Embedded Systems (WAMES 2004), Boston, USA (2004) 1214.

[47] J. A. Stankovic, Q. Cao, T. Doan, L. Fang, Z. He, R. Kiran, S. Lin, S. Son, R. Stoleru, A. Wood, Wireless Sensor Networks for In-Home Healthcare: Potential and Challenges, High Confidence Medical Device Software and Systems (HCMDSS) Workshop, Philadelphia, PA, USA (2005).

[48] V.A. Kottapalli, Two-tiered wireless sensor network architecture for structural health monitoring, Proceedings of the SPIE - The International Society for Optical Engineering USA -2003, 5057, (2003) 819.

[49] M. Barnes, H. Leather, D.K. Arvind, Emergency Evacuation using Wireless Sensor Networks, Proc. of the 32nd IEEE Conference on Local Computer Networks. LCN 2007, Clontarf Castle, Dublin, Ireland (2007) 851 857.

[50] G. Wickler, S. Potter, Information-gathering: from sensor data to decision support in three simple steps, Inf. Sys. J., 3(1) (2009) 142.

[51] L. Yang, R. Prasanna, M. King, Situation Awareness Oriented User Interface Design for Fire ER, J. Emerg. Manage., 7(2) (2009) 6574.

[52] L. Yang, R. Prasanna, M. King, On-Site Information Systems Design for Emergency First Responders. J. Inf. Technol. Theory Appl., 10(1) (2009) 527.

[53] ZigBee Alliance, Electronic Text at, <http://www.zigbee.org/> (last accessed in February 2012)

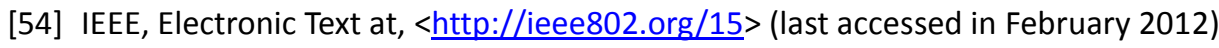

[55] P. Baronti, P. Pillai, V. W.C. Chook, S. Chessa, A. Gotta, Y. F. Hu, Wireless sensor networks: A survey on the state of the art and the 802.15.4 and ZigBee standards, Comput. Commun., 30 (2007) 16551695. 
[56] M. S. Hossen, A. F. M. S. Kabir, R. H. Khan, A. Azfar, Interconnection between 802.15.4 Devices and IPv6: Implications and Existing Approaches, Int. J. Comput. Sci. Issues, 7(1:1) (2010) 1931.

[57] Y. Liu, Design of an inventory management system based on RFID and WSNs, RF J. in RFID, (2007), Electronic Text at, http://tech.rfidworld.com.cn/2007_9/ 20079271110261739.html (last accessed in February 2012)

[58] R. Jedermann, C. Behrens, D. Westphal, W. Lang, Applying Autonomous sensor systems in logistics-Combining sensor networks, RFIDs and software agents, Sens. And Actuators A: Phys., 132 (1) (2006) 370375.

[59] S.H. Yang, Internet-based Control Systems Design and Applications, Springer, London, 2011, 173.

[60] J. Pasley, How BPEL and SOA are changing web services development, IEEE Internet Comput. 9(3) (2005) 6067.

[61] Y. Yao, J. Gehrke, The Cougar Approach to In-network Query Processing in Sensor Network, SIGMOD record, 31(3) (2002) 918.

[62] R. Govindan, W. Hong, S. Madden, M. Franklin, and S. Shenker. The sensor network as a database. University of Southern California, Los Angeles, CA, Technical Report Number TR02-02-771, September 2002.

[63] OGC, Sensor Web Enablement, http://www.opengeospatial.org/projects/groups/sensorwebdwg (last accessed in February 2012)

[64] R. Prasanna, L. Yang, M. King, GDIA: A Cognitive Task Analysis Protocol to Capture the Information Requirements of Emergency First Responders. Proceedings of the 6th International ISCRAM Conference. Gothenburg, Sweden (2009). 
[65] D.L. Goodhue, R.L. Thompson, Task-technology fit and individual performance, MISQ., 34(2) (1995) 213 236.

[66] Fire Service Manual $3^{\text {rd }}$ edition (2008) Volume 2 - Fire Service Operations, Crown Copyright 2008, UK.

[67] J. Landgren, Making action visible in time-critial work, Proceedings of ACM conference on human factors in computing systems, Montreal, Quebec, Canada (2006) 201210.

[68] D. Berrouard, K. Cziner, A. Boukalov, Emergency Scenario User Perspective in Public Safety Communications Systems, Proceedings of the 3rd Information Systems for Crisis Response and Management Conference (ISCRAM2006), Newark, NJ, USA (2006) 386396.

[69] M. Kristensen, M. Kyng, L. Palen, Parciciparoty design in emergency medical service: designing for future practice, Proceedings of ACM conference on human factors in computing systems, Montreal, Quebec, Canada (2006) 161170.

[70] M. de Leoni, F. de Rosa, A. Marrella, M. Mecella, A. Poggi, Emergency management: from user requirements to a flexible $\mathrm{P} 2 \mathrm{P}$ architeture, Proceedings of the 4th Information Systems for Crisis Response and Management Conference ISCRAM2007 (B. Van de Walle, P. Burghardt and C. Nieuwenhuis, eds) (2007) 271279.

[71] J. Robillard, R.C. Sambrook, USAF Emergency and Incident Management Systems: A Systematic Analysis of Functional Requirements, White paper for United States Air Force Space Command, 2008, Electronic Text at, http://www.uccs.edu/ rsambroo/Research/EIM_REQS.pdf (last accessed in February 2012)

[72] X. Jiang, J. I. Hong, L. A. Takayama, J. A. Landay, Ubiquitous computing for firefighters: field studies and prototypes of large displays for incident command. Proceedings of the SIGCHI Conference on Human Factors in Computing Systems, Vienna, Austria (2004) 679686. 
[73] S. Li, J.K. Visich, Radio frequency identification: supply chain impact and implementation challenges, Int. J. Integr. Supply Management, 2 (4) (2006) 407424.

[74] M. Tajima, Strategic value of RFID in supply chain management, J. Purch. and Supply Chain Manage., 13 (4) (2007) 261273.

[75] A. Ahmed, L. Sugianto, What benefit can be brought forward by adopting RFID in Emergency management, Proceedings of Second International Conference on Engineering Systems Management and Its Applications (ICESMA), Sharjah, UAE (2010) 16.

[76] J. Curtin, R.J. Kauffman, F.J. Riggins, Making the 'MOST' out of RFID technology: a research agenda for the study of the adoption, usage and impact of RFID, Inf. Technol. Manage., 8(2) (2007) 87110.

[77] L. Ramirez, S. Denef, T. Dyrks, Towards human-centred support for indoor navigation, CHI, Boston, USA, (2009) 12791282.

[78] L. Yang, On-Site Information Sharing for Emergency Response Management, J. Emerg. Manage., 5(5) (2007) 5564.

[79] D.C. Yen, C.S. Wu, F.F. Cheng, Y.W. Huang, Determinants of users' intention to adopt wireless technology: An empirical study by integrating TTF with TAM, Comput. Hum. Behav., 26(5) (2010) 906915.

[80] A. Usoro, S. Shoyelu, M. Kuofie, task-technology fit and technology acceptance models applicability to e-Tourism, J. Econ. Dev., Manage., IT, Finance and Mark., 2(1) (2010) 132.

[81] C. Chakrapani, Statistics in market research, Oxford University Press, 2004, 163-178. 
Table $1 \mathrm{~A}$ tabular model of information requirements for ER operations.

\begin{tabular}{|c|c|c|c|c|}
\hline & Mobilization & $\begin{array}{l}\text { Front-end } \\
\text { Preliminary } \\
\text { situation } \\
\text { assessment }\end{array}$ & Intervention & $\begin{array}{l}\text { Back-end } \\
\text { (command } \\
\text { centre) }\end{array}$ \\
\hline $\begin{array}{l}\text { Priority of } \\
\text { the tasks }\end{array}$ & $\begin{array}{l}\text { Prepare first } \\
\text { responders } \\
\text { and make } \\
\text { sense of what } \\
\text { will face them } \\
\text { upon arrival }\end{array}$ & $\begin{array}{l}\text { Decide the } \\
\text { tactical mode } \\
\text { and the } \\
\text { request of } \\
\text { additional } \\
\text { resources }\end{array}$ & $\begin{array}{l}\text { Reduce the loss } \\
\text { caused by the } \\
\text { accident and } \\
\text { ensure the } \\
\text { safety of the fire } \\
\text { crew }\end{array}$ & $\begin{array}{l}\text { Optimize } \\
\text { resource } \\
\text { allocation and } \\
\text { dispatch }\end{array}$ \\
\hline $\begin{array}{l}\text { Category of } \\
\text { information }\end{array}$ & $\begin{array}{l}\text { Environmental } \\
\text { conditions }\end{array}$ & $\begin{array}{l}\text { Environmental } \\
\text { conditions, } \\
\text { available } \\
\text { resources }\end{array}$ & $\begin{array}{l}\text { Environnemental } \\
\text { conditions, } \\
\text { information on } \\
\text { response } \\
\text { participants, } \\
\text { status of } \\
\text { casualties, } \\
\text { available } \\
\text { resources }\end{array}$ & $\begin{array}{l}\text { Environnemental } \\
\text { conditions, } \\
\text { information on } \\
\text { response } \\
\text { participants, } \\
\text { status of } \\
\text { casualties, } \\
\text { available } \\
\text { resources }\end{array}$ \\
\hline $\begin{array}{l}\text { Requester of } \\
\text { the } \\
\text { information }\end{array}$ & $\begin{array}{l}\text { Incident } \\
\text { commanders, } \\
\text { fire fighters }\end{array}$ & $\begin{array}{l}\text { Incident } \\
\text { commanders }\end{array}$ & $\begin{array}{l}\text { Incident } \\
\text { commanders, } \\
\text { fire fighters }\end{array}$ & $\begin{array}{l}\text { The command } \\
\text { centre }\end{array}$ \\
\hline $\begin{array}{l}\text { Source of } \\
\text { information }\end{array}$ & $\begin{array}{l}\text { Command } \\
\text { centre, central } \\
\text { database, } \\
\text { physical } \\
\text { sensors } \\
\text { installed in the } \\
\text { incident scene, } \\
\text { Internet }\end{array}$ & $\begin{array}{l}\text { Local people, } \\
\text { physical } \\
\text { sensors } \\
\text { installed in the } \\
\text { incident scene }\end{array}$ & $\begin{array}{l}\text { Local people, } \\
\text { on-site officers, } \\
\text { physical sensors } \\
\text { installed in the } \\
\text { incident scene }\end{array}$ & $\begin{array}{l}\text { Non emergency } \\
\text { personnel, } \\
\text { on-site officers, } \\
\text { central } \\
\text { database, } \\
\text { Internet }\end{array}$ \\
\hline $\begin{array}{l}\text { Richness of } \\
\text { information }\end{array}$ & Low & Medium & Medium & High \\
\hline $\begin{array}{l}\text { Importance } \\
\text { in real-time }\end{array}$ & Important & Very important & $\begin{array}{l}\text { Extreme } \\
\text { important }\end{array}$ & Less important \\
\hline
\end{tabular}


Table 2 Attributes used for measurement.

\section{Attributes used for measurement}

\section{Information requirements characteristics (IRC)}

First responders have little information about the accident on the way to scene $\left(\operatorname{IRC}_{1}\right)$.

First responders have little knowledge of the situation inside a premise $\left(\mathrm{IRC}_{2}\right)$.

Maintaining the accountability of resources and personnel and tracing their exact location is crucial but not always achievable $\left(\mathrm{IRC}_{3}\right)$.

Decision could be made much efficiently and accurately if better situational awareness through multiple sources of information is achieved $\left(\mathrm{IRC}_{4}\right)$.

Resource allocation is often carried out less optimally due to lack of the visibility of resources on scene or dispatched to other places early $\left(\mathrm{IRC}_{5}\right)$.

\section{IoT technology characteristics (ITC)}

IoT technology is a global and real-time solution $\left(\mathrm{ITC}_{1}\right)$.

IoT technology possesses the ability to wirelessly provide comprehensive type of data about the surroundings $\left(\mathrm{ITC}_{2}\right)$.

IoT technology possesses the ability to monitor the environments and trace and track objects $\left(\mathrm{ITC}_{3}\right)$.

\section{Requirements-technology fit (RTF)}

Accountability of resources and personnel on scene or on the way to scene is always up-to-date and accurate $\left(\mathrm{RTF}_{1}\right)$.

Assessment of the situation, regardless of indoor or outdoor environments, is well 
supported by multiple sources of information $\left(\mathrm{RTF}_{2}\right)$.

Resource allocation is well supported by the visibility of response forces and their remaining capability $\left(\mathrm{RTF}_{3}\right)$.

Coordination among various participating organizations is well supported by the ERIS $\left(\mathrm{RTF}_{4}\right)$.

\section{Strategic value (SV)}

Efficient cooperation between various organizations $\left(\mathrm{SV}_{1}\right)$.

Accurate situational awareness and complete visibility of disaster development $\left(\mathrm{SV}_{2}\right)$.

Complete visibility of response forces and their remaining capability $\left(\mathrm{SV}_{3}\right)$.

Table 3 Effect matrix between information requirements characteristics, loT technology characteristics and requirements-technology fit

\begin{tabular}{|c|c|c|c|c|c|c|c|c|c|c|c|c|}
\hline $\mathrm{H}_{1}$ & & $\mathrm{RTF}_{1}$ & & & $\mathrm{RTF}_{2}$ & & & $\mathrm{RTF}_{3}$ & & & $\mathrm{RTF}_{4}$ & \\
\hline & $\mathrm{ITC}_{1}$ & $\mathrm{ITC}_{2}$ & $\mathrm{ITC}_{3}$ & $\mathrm{ITC}_{1}$ & $\mathrm{ITC}_{2}$ & $\mathrm{ITC}_{3}$ & $\mathrm{ITC}_{1}$ & $\mathrm{ITC}_{2}$ & $\mathrm{ITC}_{3}$ & $\mathrm{ITC}_{1}$ & $\mathrm{ITC}_{2}$ & $\mathrm{ITC}_{3}$ \\
\hline $\mathrm{IRC}_{1}$ & 4.25 & 3.2 & 4.85 & 2.5 & 2.1 & 2.4 & 1.5 & 1.3 & 4.2 & 3.2 & 2.25 & 1.25 \\
\hline $\mathrm{IRC}_{2}$ & 2.85 & 2.2 & 4.4 & 3.36 & 4.95 & 4.2 & 2.2 & 2.35 & 3.24 & 1.35 & 1.25 & 2.95 \\
\hline $\mathrm{IRC}_{3}$ & 4.95 & 3.0 & 4.85 & 3.25 & 4.1 & 4.85 & 4.35 & 3.1 & 4.35 & 2.95 & 3.1 & 3.15 \\
\hline $\mathrm{IRC}_{4}$ & 2.38 & 3.18 & 2.15 & 4.05 & 4.98 & 4.98 & 2.0 & 3.48 & 3.26 & 4.35 & 4.45 & 4.1 \\
\hline $\mathrm{IRC}_{5}$ & 1.85 & 1.55 & 1.5 & 2.15 & 1.95 & 3.1 & 4.2 & 3.21 & 4.98 & 2.45 & 2.12 & 2.98 \\
\hline
\end{tabular}


Table 4 Effect matrix between requirements-technology fit and strategic value

\begin{tabular}{llll}
\hline $\mathbf{H}_{2}$ & SV1 & SV2 & SV3 \\
\hline RTF1 & 4.25 & 2.25 & 4.85 \\
RTF2 & 2.5 & 4.95 & 3.25 \\
RTF3 & 4.35 & 2.25 & 4.90 \\
RTF4 & 4.85 & 3.30 & 4.20 \\
\hline
\end{tabular}

Table 5 Binary effect matrix between information requirements characteristics, loT technology characteristics and requirements-technology fit

\begin{tabular}{|c|c|c|c|c|c|c|c|c|c|c|c|c|}
\hline $\mathbf{H}_{1}$ & & $\mathrm{RTF}_{1}$ & & & $\mathrm{RTF}_{2}$ & & & $\mathrm{RTF}_{3}$ & & & $\mathrm{RTF}_{4}$ & \\
\hline & $\mathrm{ITC}_{1}$ & $\mathrm{ITC}_{2}$ & $\mathrm{ITC}_{3}$ & $\mathrm{ITC}_{1}$ & $\mathrm{ITC}_{2}$ & $\mathrm{ITC}_{3}$ & $\mathrm{ITC}_{1}$ & $\mathrm{ITC}_{2}$ & $\mathrm{ITC}_{3}$ & $\mathrm{ITC}_{1}$ & $\mathrm{ITC}_{2}$ & $\mathrm{ITC}_{3}$ \\
\hline $\mathrm{IRC}_{1}$ & 1 & 0 & 1 & 0 & 0 & 0 & 0 & 0 & 1 & 0 & 0 & 0 \\
\hline $\mathrm{IRC}_{2}$ & 0 & 0 & 1 & 0 & 1 & 1 & 0 & 0 & 0 & 0 & 0 & 0 \\
\hline $\mathrm{IRC}_{3}$ & 1 & 0 & 1 & 0 & 1 & 1 & 1 & 0 & 1 & 0 & 0 & 0 \\
\hline $\mathrm{IRC}_{4}$ & 0 & 0 & 0 & 1 & 1 & 1 & 0 & 0 & 0 & 1 & 1 & 1 \\
\hline $\mathrm{IRC}_{5}$ & 0 & 0 & 0 & 0 & 0 & 0 & 1 & 0 & 1 & 0 & 0 & 0 \\
\hline
\end{tabular}


Table 6 Binary effect matrix between requirements-technology fit and strategic value

\begin{tabular}{llll}
\hline $\mathrm{H}_{2}$ & SV1 & SV2 & SV3 \\
\hline RTF1 & 1 & 0 & 1 \\
RTF2 & 0 & 1 & 0 \\
RTF3 & 1 & 0 & 1 \\
RTF4 & 1 & 0 & 1 \\
\hline
\end{tabular}


Fig. 1. The basic task-technology fit model.

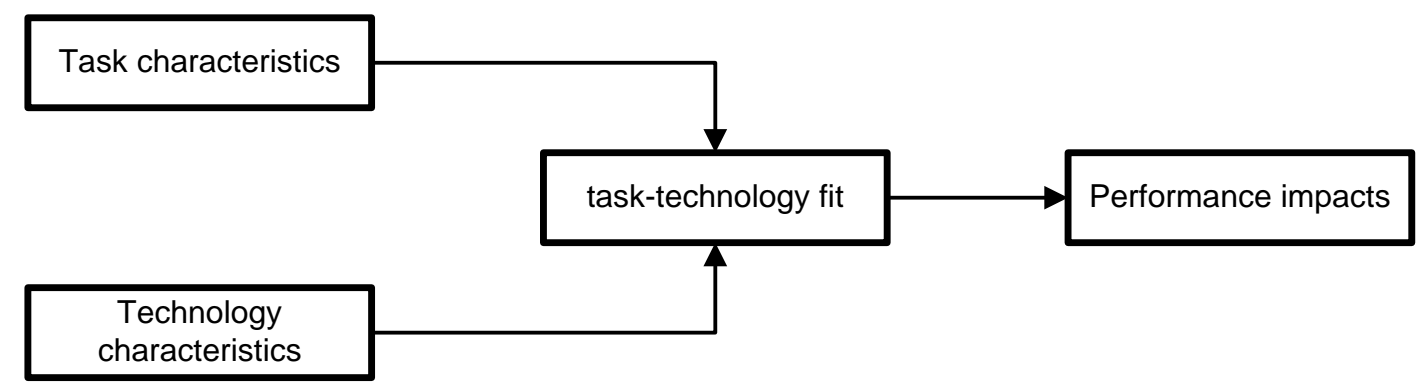

Fig. 2. Proposed research model for the loT technology.

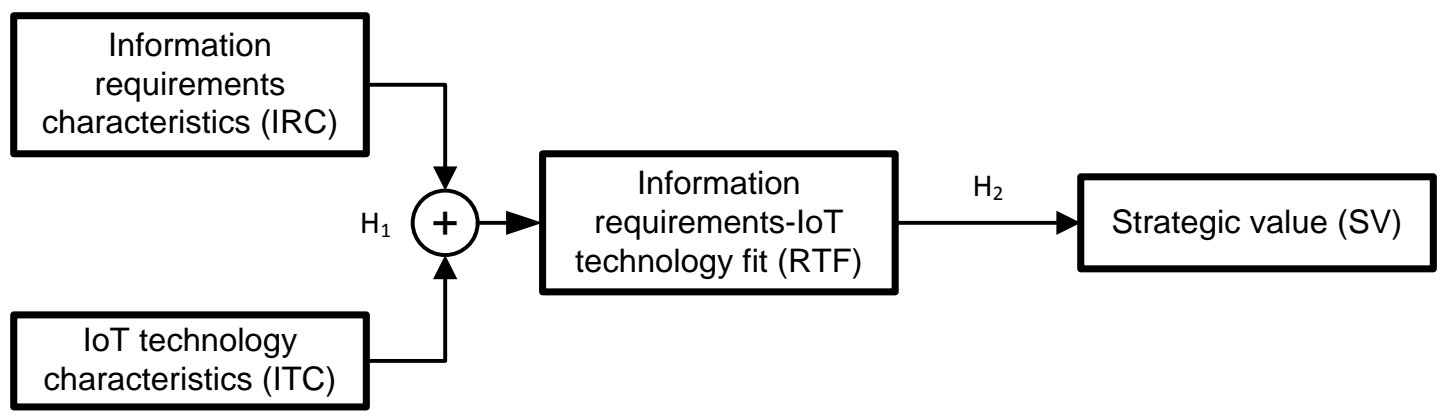

